\title{
EL APOSTOLADO SOCIAL DE LA PROVINCIA JESUITA BÉTICA
}

\author{
WENCESLAO SOTO ARTUÑEDO, S.I. ${ }^{1}$
}

RESUMEN: Este trabajo presenta el apostolado social en la provincia Bética en la Edad Contemporánea, si bien con referencias al resto de España. En él se dan diversas etapas u oleadas en las que con fuerza renovada los jesuitas andaluces retoman este ministerio, impregnándolo de alguna novedad y manteniendo herencias precedentes. Así se muestra que, si bien el interés de la Compañía por el mundo de los necesitados es de siempre, en cada lugar y tiempo busca expresiones nuevas que se mueven entre labores asistenciales, educativas y politicas.

Palabras clave: Compañía de Jesús; Andalucía; apostolado social; mundo obrero.

\section{The Social apostolate of the Jesuit province of Bética}

ABSTRACT: This work presents the social apostolate in the province of Bética in the Contemporary Age, although with references to the rest of Spain. There are various stages or waves in which the Andalusian Jesuits take up this ministry with renewed strength, imbuing it with some novelty and maintaining previous legacies. This shows that, although the Society's interest in the world of the needy remains constant, in every place and time it seeks new expressions that move between welfare, educational and political work.

KEY WORDS: Society of Jesus; Andalusia; social apostolate; working world.

El P. Manuel Revuelta, en sus amplias investigaciones, ha trazado los itinerarios de todos los ámbitos de la historia de los jesuitas en la España contemporánea. Uno de los temas que irrumpen con fuerza en el periodo de la última parte del siglo XIX es el del apostolado social, un gran esfuerzo de la Iglesia que reaccionó, así, con él, a la fuga masiva de la Iglesia, por parte del mundo obrero, después del cambio cultural producido por la revolución industrial. El P. Manuel Revuelta en su tomo III de la Historia de la Compañía de Jesús en la España contemporánea se ocupa de las acciones apostólicas de los jesuitas hasta 1912, bajo el título: Palabras y fermentos. En él pasa revista al apostolado de la palabra (misiones populares y Ejercicios) y la

${ }^{1}$ Archivum Romanum Societatis Iesu en Roma. Correo electrónico: arsi-soto@sjcuria.org. 
cooperación de los seglares en las asociaciones (Apostolado de la Oración, Congregaciones Marianas, y círculos y sindicatos obreros católicos). Incluye el apostolado social en un conjunto de actividades bien diversas relacionadas con la cooperación de seglares en asociaciones, pero, en realidad, el apostolado social tiene una entidad propia. Esta publicación se completa con su artículo "Atención a los marginados en los colegios de jesuitas» (Revuelta González, 2006), sobre un aspecto muy concreto del interés por los pobres.

En ese ámbito del apostolado social se inscribe esta aportación, pero circunscrita a la provincia Bética en la Edad Contemporánea, si bien con referencias al resto de España. Este apostolado se ha presentado en distintos momentos u oleadas, que, sin rompimiento con lo anterior, han supuesto cierta novedad específica. Así se muestra que, si bien el interés de la Compañía por el mundo de los necesitados es de siempre, en cada lugar y tiempo busca expresiones nuevas ${ }^{2}$.

\section{INTRODUCCIÓN}

Por el año de 1972, yo trabajaba en Santana Motor de Linares (Jaén) con contrato de aprendizaje como delineante industrial, según el convenio, entonces en extinción, entre la empresa y la SAFA (Escuelas Profesionales de la Sagrada Familia) de Linares, mientras esperaba ser admitido en el noviciado de los jesuitas. En aquel momento, que era un tiempo de discernimiento de la propia vocación, yo me había elaborado un prejuicio sobre los jesuitas que inútilmente intentaron disolver algunos compañeros de trabajo que atisbaron mi proceso personal. Linares y sus alrededores había sido el escenario de mi vida y, como muestra de toda la realidad, era lo que había configurado mi imaginario personal. Así, concluí que los jesuitas educaban a los pobres. Me lo mostraba mi propia experiencia en la SAFA de Linares, así como lo que conocía de otras escuelas de la misma fundación cercanas como la de Úbeda y Andújar (donde ese curso estudié el pre-COU, con dispensa de asistir a clase) y la referencia que tenía de otras. En esa composición de lugar particular mía, quienes educaban a los ricos eran los salesianos, que tenían los colegios privados. Eso me dictaba también mi experiencia: el colegio de San Agustín, de Linares y el de Santo Domingo Savio, de Úbeda (donde estudió bachillerato Joaquín Sabina).

2 Agradezco a Ildefonso Camacho, José Juan Romero e Ignacio Molina la revisión de este trabajo y sugerencias. 
Con esa percepción tan simplista ingresé en la Compañía en 1973. Después aprendí que la realidad era más compleja y completa: Que los jesuitas también tenían colegios privados para ricos y que los salesianos también se ocupaban de educar a gente sencilla y menos pudiente... Incluso me encontré con que mucha gente mantenía el prejuicio contrario al ingenuo primero mío: que los jesuitas tenían su hábitat natural entre los ricos y poderosos y los salesianos entre los desfavorecidos.

Ya en el noviciado entró en crisis aquella concepción: Pero, entonces, los jesuitas, ¿están con los ricos o con los pobres? Esta pregunta, como casi todas las dicotomías, es falsa si se plantea en términos excluyentes, pues los jesuitas están con los ricos y también con los pobres. Pero eso no es lo más importante, sino que lo es esta otra pregunta: ¿qué hacen con unos y con otros? ¿qué pretenden? ¿lo propio suyo es cultivar la fe o también las obras de misericordia ya sea en su formulación tradicional o contemporánea? Las respuestas pueden ser múltiples. La que ofrecen los propios jesuitas es que intentan educar a las élites sociales para que utilicen su influjo social en mejorar la sociedad; a los pobres les posibilitan un desarrollo personal que, poco a poco, transformará la sociedad. Piden a los ricos para ayudar a los pobres en sus calamidades, incluso intentan atender a las personas que sufren alguna deficiencia o injusticia, independientemente de su cuenta corriente... Otros dicen que donde se sienten a gusto los jesuitas es con los ricos y tratando de temas de fe, pero por deber de conciencia, tienen que atender a los pobres, como una obligación que recae sobre algunos miembros para lavar la imagen corporativa.

Hay una corriente historiográfica que interpreta que a los jesuitas lo que les interesa es conseguir poder económico, social y político; y dominar las conciencias importantes a través del confesionario, y el pensamiento de las masas a través de las predicaciones, asumiendo como ciertas las instrucciones del escrito apócrifo Monita Secreta ${ }^{3}$. Por eso se apegan a los ricos ${ }^{4}$.

Para intentar dar otra respuesta a estas preguntas nos acercamos a una realidad concreta, a la de la provincia Bética (Andalucía y Canarias) en la Edad Contemporánea. Para concretar el enraizamiento de la provincia Bética en la tradición jesuita, tenemos que referirnos, aunque sea fugazmente, a los documentos fundacionales de la Compañía de Jesús, las primeras formulaciones de su identidad y misión, ya que suponen el marco que legitima e

3 Monita privata Societatis Jesu, Notobirg, 1612; Pavone (2005 y 2006), Soto Artuñedo (Proyección 2008).

4 Esa es la tesis de algunos historiadores, uno de cuyos representantes puede ser Julián José Lozano Navarro (2005). Ver la crítica demoledora, en concreto, a este trabajo, de García Hernán (2007). 
inspira las diversas actividades de los jesuitas en todas las épocas históricas. Son un germen que se irá desplegando en cada tiempo y lugar.

\section{LA ANTIGUA COMPAÑÍA}

En las deliberaciones de marzo a junio de 1539, en las que aquellos «amigos en el Señor» procedentes de París decidieron ser los primeros compañeros de una nueva orden religiosa, también redactaron el núcleo de su reglamentación, conocido como Quinque Capitula, aprobado verbalmente por Paulo III el 3 de septiembre de $1539^{5}$, e incluido en otro documento conocido como la Fórmula del Instituto ${ }^{6}$ aprobada inicialmente en 1540 y después en la Fórmula de 1550, más completa. En esta última se expresa así el fin de la Compañía:

para emplearse en la defensa y propagación de la fe y en el provecho de las almas en la vida y doctrina cristiana, sobre todo por medio de las públicas predicaciones, lecciones y cualquier otro ministerio de la palabra de Dios, de los ejercicios espirituales, la doctrina cristiana a los niños y gente ruda, y el consuelo espiritual a los fieles, oyendo sus confesiones y administrándoles los sacramentos. Y con todo, se muestre disponible a la pacificación de los desavenidos, socorro de los presos en las cárceles y de los enfermos en los hospitales, y el ejercicio de las demás obras de misericordia [...]. Haciendo todo esto gratuitamente ${ }^{7}$.

Este párrafo tan programático como denso nos delinea las dos dimensiones entre las que se desarrollarán las actividades de la Compañía: propagación de la fe y obras de misericordia. No es un binomio antitético, sino coordenadas en las que se sitúa, en distintos grados, el quehacer de todos los jesuitas. Especifica los distintos destinatarios de la actividad de los jesuitas (niños, gente inculta, fieles, personas desavenidas, presos, enfermos) y las distintas actividades que deben realizar tanto para el cultivo humano y espiritual (predicaciones, lecciones ${ }^{8}$, "otros ministerios de la palabra»,

5 Jiménez Oñate (1966); Osuna (1998); Churruca Peláez (1999).

6 La Fórmula del Instituto fue aprobada oficialmente el 27 de septiembre de 1540, por la bula Regimini Militantis Ecclesiae, de Paulo III, y por Julio III en la bula Exposcit debitum de 21 de julio de 1550. Aldama (1977).

7 «Fórmula del Instituto de 1550», en Loyola (2013).

8 En el primer borrador de las Constituciones (1541) se excluían las centros educativos propios: "No estudios ni lectiones en la Compañía» (Monumenta Ignatiana, Constitutiones I, 47), pero en la evolución de los primeros años, el mismo San Ignacio comprendió la importancia de los colegios como potencial apostólico, no solo 
ejercicios espirituales, doctrina cristiana, consuelo espiritual, confesiones, otros sacramentos) como para atender otras necesidades menos espirituales (pacificación, socorro, otras obras de misericordia). Aquí caben tanto ricos como pobres, y las necesidades espirituales, culturales, sociales y hasta las puramente físicas.

La palabra utilizada en la versión latina de la Formula del Instituto de 1550 como nexo entre unos y otros ministerios es nihilominus, traducida aquí por "y con todo». Se puede traducir como «también»o «sin embargo», con lo que parece que se están priorizando los ministerios espirituales, en línea con la parte VII de las Constituciones; pero también se puede interpretar que dice "nihilo minus", es decir, y no menos importante que los ministerios espirituales de la predicación y sacramentos es estar dispuesto para los de la «justicia» u obras de misericordia ${ }^{9}$.

Esta doble dimensión explica que, desde el principio, veamos a los jesuitas ocupados más directamente en tareas que tienen que ver con el servicio a la fe, pero también en otras en las que actúan más específicamente como plasma o bálsamo para curar las heridas del mundo, incluso posibilitando y promoviendo cambios estructurales. Así, en la antigua Compañía, antes de su expulsión de España de 1767 y la supresión de 1773, los jesuitas predicaban en púlpitos y plazas, enseñaban en cátedras y clases, confesaban, decían misa, orientaban Ejercicios Espirituales, explicaban catecismo a niños y adultos incultos,... y también servían en los hospitales y en las cárceles de entonces, buscando recursos para ayudar a los pobres y trabajando en las distintas calamidades que asolaban periódicamente las poblaciones (peste, inundaciones, terremotos...). Además, pusieron en marcha iniciativas para alfabetizar a pobres, tanto en las misiones como en Europa ${ }^{10}$.

Una de estas instituciones promovidas por los jesuitas en España, que sobrevive al día de hoy, es la hermandad del Refugio. La primera se fundó en Madrid, a mediados del siglo XVII, promovida por el jesuita Bernardino de Antequera. Su finalidad era albergar y alimentar a los pobres, conduciendo a éstos y a los dementes a los establecimientos donde pudieran ser atendidos, amparar niños expósitos, costear la lactancia a los niños de familias pobres, pagar lavados y baños a los menesterosos, dotar doncellas,

de centros de formación para los propios jesuitas, sino para el público en general, y promovió un cambio trascendental, de manera que los colegios acabaron siendo el establecimiento más representativo de la Compañía de Jesús. Ver Peter-Hans Kolvenbach (2003), 30; Soto Artuñedo (2017).

9 Agradezco esta apreciación a Guillermo Rodríguez-Izquierdo.

10 Ver, por ejemplo, Arranz Roa (2004) o Soto Artuñedo (2004). 
socorrer madres abandonadas y ayudar a domicilio a los pobres vergonzantes (Corral, 1998).

\section{LA COMPAÑÍA RESTAURADA}

La Compañía restaurada en 1814 retoma el mismo abanico de actividades, y lo actualiza y amplía, como una respuesta sensible a los distintos contextos, tan distintos de la antigua Compañía, si bien no inmediatamente. Por lo que respecta al eje pobres/obreros/educación podemos distinguir cuatro momentos especiales, a modo de oleadas, en los que la sensibilidad de los jesuitas alumbró formas nuevas de ejercer su doble ministerio en perspectiva de apostolado social ${ }^{11}$.

La provincia jesuita Bética como tal, no aparecerá hasta 1924, pues hasta ese año el territorio de Andalucía estaba integrado en la provincia de Toledo. Al principio abarcó sólo el territorio de Andalucía y en 1952 incorporó el de las Islas Canarias, que hasta entonces habían estado integradas sucesivamente en las provincias de España (1815), Aragón (1863), Toledo (1880) y Castilla (1920).

\subsection{PRIMERA OlEAdA (1880-1932)}

El desarrollo económico e industrial del siglo XIX hizo más visibles y llamativas las penurias y penalidades injustas de los trabajadores. Apareció así la «cuestión social», que puso el foco en la mala situación socioeconómica de los trabajadores. Parte de este movimiento fue el conocido como «catolicismo social»(Andrés-Gallego, 1997, pp. 835-867).

La jerarquía eclesiástica también fue sensible a esta situación y el mismo pontífice León XIII promulgó la encíclica Rerum Novarum (1891), el primer documento del magisterio de la Iglesia que estudiaba el problema social ocasionado por la industrialización y el nuevo modelo económico que luego será llamado capitalismo. Rechaza directamente el socialismo, tal como se entendía entonces, y, aunque no menciona explícitamente al liberalismo, describe y rechaza elementos típicos del liberalismo económico de aquel tiempo. Habla del derecho a la propiedad, aunque subrayando su valor social; atribuía al Estado el papel de promotor del bien común, de la prosperidad

11 Czerny y Foglizzo (2008); Álvarez de los Mozos (2018). http://www.cpalsj.org/ wp-content/uploads/2013/06/ElApostoladoSocialSigloXX.pdf 
pública y de la privada; reconocía al obrero el derecho a un salario justo; condenaba la lucha de clases; y aceptaba el derecho del obrero a asociarse para la defensa de sus intereses, incluso en asociaciones compuestas exclusivamente por obreros ${ }^{12}$.

La Rerum Novarum fue un aldabonazo en España, y, aunque su doctrina resultó incómoda para la clase política y la burguesía, tuvo un prolongado influjo. Su publicación movilizó a un grupo de propagandistas a diversos niveles (conferencias, asambleas, etc.), y promovió cinco catecismos para divulgarla. A pesar de que estos grupos fueron minoritarios, dinamizaron la sensibilidad social que ya estaba produciendo frutos. Esto hace que a finales del XIX proliferen las organizaciones obreras católicas, algunas de ellas anteriores a las socialistas, anarquistas y a la propia Rerum Novarum. Eran obras benéfico-asociativas y educativas, como la Asociación de Amigos de los Obreros y los Patronatos de la Juventud Católica. El catolicismo social se interesó especialmente por la educación del mundo obrero:

Pero del catolicismo social nos interesa destacar su preocupación y su acción educativa. Porque si bien pueden achacársele deficiencias e incluso reconocérsele un determinado fracaso inicial en los ámbitos social y laboral, no puede dejársele de tener en cuenta en lo que respecta a su honda preocupación por la instrucción del obrero y proletario en general en el marco de ese "regeneracionismo» por la educación, denominador común de toda una época. Desde este contexto, la iglesia creó escuelas nocturnas y dominicales para obreros e hijos de obreros, Círculos de Estudios Sociales; Universidades Populares, etc., en un intento por elevar el nivel cultural del más amplio de los sectores sociales, sin que nos detengamos aquí a valorar el alcance real y las motivaciones últimas de tales iniciativas. (Ruiz Rodrigo y Palacio Lis, 1986, pp. 285-286)

Los jesuitas fueron permeables a esta sensibilidad, y a partir de la restauración canovista, coincidiendo con una fase de tranquilidad ${ }^{13}$ y de expansión, configuraron un nuevo apostolado social en línea con el deseo de León XIII de educar y cristianizar al mundo obrero. Así, por ejemplo, en la congregación provincial de Aragón de 1892 se aprobó un postulado para el P. General pidiéndole que, ante la magnitud del problema social, fomentara entre los jesuitas el interés por ayudar a los obreros por medio de las instituciones dedicadas a ellos, escuelas nocturnas y diurnas, misiones, catequesis y otras obras de caridad propuestas por los pontífices, necesarias para la sociedad y compatibles con los fines de la Compañía; y que, si parecía conveniente,

12 Camacho (1984) (1986); Llorca (1999), pp. 328-331.

13 Recordamos que, en España, en el siglo XIX fueron expulsados los exjesuitas que habían vuelto por autorización de 1798 (1801) y disueltos tres veces (1820-23, $1834-51$ y $1868-74)$. 
escribiera una instrucción práctica sobre el apostolado con los obreros y el modo y límites para realizarlo (Revuelta González, 1991, p. 551).

También surgieron sindicatos católicos en 1897, con un mayor desarrollo entre 1919 y 1936, si bien siempre fueron débiles y tachados de amarillos. Tuvo más consistencia la confederación Nacional Católica Agraria del jesuita Sisinio Nevares ${ }^{14}$, que fue potente en zonas agrarias hasta su desaparición entre 1937 y 1940, al articularse la organización sindical del Estado franquista. No obstante, las actividades sindicales fueron monopolizando la atención y los esfuerzos de muchos católicos sociales en detrimento de las iniciativas reformistas y educativas, lo que precipitó el final de la mayoría de los círculos católicos obreros ${ }^{15}$.

Los Círculos Católicos Obreros fueron un modelo organizativo que tuvo especial éxito en Levante en el ámbito del jesuita Antonio Vicent ${ }^{16}$. En 1892, en los 40 círculos de la diócesis de Valencia había 27 patronatos juveniles

14 Sisinio Nevares nació el 11.05.1878 en Carrión de los Condes, ingresó en la Compañía el 14.07.1893, hizo los últimos votos el 02.02.1911 y murió en Valladolid el 19.05.1946. Escribió al P. General desde Valladolid el 12.02.1920, denunciando que los jesuitas se dedicaban poco de la formación espiritual y social de los obreros y de sus hijos, pues creía que la Compañía debía apostar en aquellos momentos por las escuelas profesionales, congregaciones marianas para obreros, ... También lamentaba la falta de formación social de los patronos, muchos de ellos padres de los alumnos de jesuitas. Carta de Nevares a Barrachina, en Aldea, J. Martín Tejedor y J. García Granda (1987), II, pp. 680-694. Citado por Revuelta González (2006), pp. 213-229, pp. 221-222; García Granda (1990); Reyes (2013) (2020). Diccionario Histórico de la Compañía de Jesús.

15 J. J. Castillo (1976), 37-75; García Nieto (1960); Sanz de Diego (1979), pp. $577-$ 664; Varios (2009).

16 Antonio Vicent nació el 2.10.1837, Castellón de la Plana; ingresó 20.10.1861, El Puerto de Santa María (Cádiz); fue ordenado el 24.12.1871, Banyoles (Gerona); hizo los últimos votos 15.08.1876, Valencia; murió 9.06.1912, Valencia. Círculos Obreros Católicos (1886-1895) es su realización más conocida. Dentro de la acción social de la Compañía de Jesús en España (Sindicalismo católico) fue cronológicamente la primera obra duradera encaminada a la asociación obrera. Era abiertamente confesional, interclasista para lograr la armonía y con amplios objetivos (religioso, económico, instructivo y recreativo). Aunque no se dispongan de cifras exactas sobre su implantación, puede afirmarse que, a final de siglo, competían en número con las organizaciones anarquistas y duplicaba, por lo menos, al sindicato de inspiración socialista, la U.G.T. (Unión General de Trabajadores). En respuesta a la Rerum Novarum (1891) de León XIII, Vicent publicó, sufragado por Claudio López Bru, marqués de Comillas, Socialismo y Anarquismo, que fue un importante comentario de la encíclica y guía doctrinal para sus Círculos. En su libro, hizo una cálida defensa de los derechos del trabajador, entre otros, el de huelga, salario familiar y participación de beneficios. Apoyado y secundado por el marqués de Comillas, y el cardenal-arzobispo de Valencia, Ciriaco M. ${ }^{a}$ Sancha, fue encargado de organizar la peregrinación obrera 
con 14 congregaciones marianas de luises; en los 11 círculos de la diócesis de Tortosa, 5 y 9 respectivamente. En el resto de España hubo alguno más. Ha tenido especial trascendencia y supervivencia el Círculo Católico de Burgos (Varios, 2009).

Otras instituciones educativas fueron las Escuelas del Ave María, creadas por el sacerdote Andrés Manjón (1846-1923) en 1889 (Pego Puigbó, 2007). El propio jesuita Vicent y otros activistas hicieron suya la idea y la extendieron por el resto de España, para cuya promoción se crearon sociedades. El prototipo de este nuevo modelo fue la Asociación Católica de Escuelas de Obreros de Valladolid, iniciada en 1881 por el jesuita Francisco de Sales Colina ${ }^{17}$, que creó un fondo de socorro mutuo y una Caja de Ahorros que convirtieron a la asociación en germen de otra más compleja que en 1885 adoptó el nuevo nombre de Asociación Católica de Escuelas y Círculos de Obreros.

A principios de siglo XX las revitalizadas preocupaciones sindicalistas hicieron ver la posibilidad de que los establecimientos educativos católicos sirvieran de centros de formación para futuros líderes sindicales. Así nació la Universidad Popular que en 1907 se estableció en el Círculo Obrero Valenciano de San Vicente Ferrer. Al año siguiente inició su actividad en Madrid el Instituto Católico de Artes e Industria (ICAI), con una Escuela de Aprendizaje para obreros y la Escuela de Peritos mecánico-electricistas (Sanz de Diego, 1993). Algunas de las actividades reformistas llegaron a emanciparse de los círculos católicos y del movimiento católico social, como las cajas de ahorro

a Roma (1894) que llevó 18.500 obreros a León XIII para agradecerle la encíclica. (Diccionario Histórico de la Compañía de Jesús).

17 Francisco de Sales Colina nació 29.01.1837, Monasterio de Rodilla (Burgos); ingresó 16.06.1856, Palma de Mallorca (Baleares); fue ordenado 1871, Salamanca; últimos votos 2.02.1873, San Sebastián (Guipúzcoa); murió 16.12.1893, Valladolid. Se preocupó tanto por el sector obrero como por el deprimido del campesinado. La indefensión de ambos grupos se agravaba por la pasividad del Estado ante los abusos del capitalismo liberal y por la falta de organizaciones de obreros y agricultores. Su primera creación fueron las «Escuelas de Obreros» con clases diurnas para los hijos de los obreros, y nocturnas para los adultos, con una asistencia inicial de cerca de 300 y unos 700 , respectivamente (1881). Dentro del vasto plan de ayuda al obrero, promovió como complemento de las escuelas nocturnas la «Comisión de Trabajo» para atender a los parados y la «Caja de Socorros Mutuos» para casos de enfermedad y accidente, cuya financiación se apoyó en las cuotas módicas de los socios obreros, las algo mayores de los jefes de taller y los donativos de los socios protectores. En 1885 nació su obra principal, el «Círculo Católico de Obreros», inspirado en la obra del P. Antonio Vicent, que inició conferencias semanales sobre temas religiosos y sociales, frente a la propaganda socialista y de la escuela laica. Trabajó también en los pueblos de Valladolid; su obra se consolidaría años más tarde con las «Cajas Rurales» y los «Sindicatos Agrícolas» del P. Sisinio Nevares. Diccionario Histórico de la Compañía de Jesús. 
y las cajas rurales. Otras instituciones como el ICAI de Madrid (1908) sobrevivieron después de la guerra civil, como una de las más prestigiosas escuelas de ingeniería de España. En Ciudad Real mantuvieron los jesuitas una escuela apostólica desde 1912 que después se transformó en centro de formación profesional traspasado a los salesianos en 1986: la Escuela Hermano Gárate (López Pego, 2003). En Valencia empiezan en 1904 unas escuelas nocturnas para obreros y en 1908 una escuela gratuita de Primera Enseñanza ${ }^{18}$, sobre la que el P. Francisco Muedra creará sus «Escuelitas» en 1925. Más tarde, fue inaugurada la Fundación Revillagigedo en Gijón y la Escuela Profesional en Natahoyo (1929) (Viña Herbón, 2000). Iniciativas similares proliferaron por todo el territorio nacional.

Un ejemplo de iniciativa de distinto carácter, pero con fuerte impacto social es la fundada en 1909 por el jesuita Ángel Ayala: la Asociación CatólicoNacional de Jóvenes Propagandistas. Posteriormente se creó en Madrid en 1912 la Agrupación de Propagandistas Sociales, que editaron periódicos por distintas localidades. Se iniciaron también instituciones netamente sociales como el Patronato de la Caridad y su Refugio en La Coruña, en 1918, que dará lugar al Instituto Benéfico Social Padre Rubinos (Varios, 2008). También dio lugar la Compañía a obras benéfico-sanitarias como la leprosería de Fontilles en $1909^{19}$.

En Andalucía, igualmente, se crearon diversas instituciones, normalmente dependientes de las residencias, no de los colegios. Ya existían círculos católicos obreros a finales de siglo XIX. Por ejemplo, en Jerez, iniciado por el P. Cadenas en 1877; otro en Málaga, en 1888, además del círculo católico para los pescadores de la barriada de El Palo (Málaga), fundado por el P. José María de La Puente en 1893, con escuela para obreros (1903).

Se crearon centros de enseñanza popular. En Sevilla había varias escuelas diurnas y nocturnas hacia 1874, y una escuela nocturna para chicas en 1881. Hacia 1901, por impulso del superior Francisco Tarín, la congregación de las Madres Cristianas fundó una escuela para niños en el barrio de la Macarena. Es el único caso en que esta congregación traspasó los fines piadosos y familiares de su congregación (Revuelta, 2008, p. 637). En Córdoba también había una escuela para niños en 1888. En Jerez se reanudó una escuela nocturna entre 1906 y 1911. En el noviciado de Granada se inauguró una escuela nocturna para obreros en 1906, donde dio clases san José M. ${ }^{a}$ Rubio, dirigida ese año por el P. Hitos. En Sevilla hay otra escuela entre 1909 y 1910 dirigida por el P. Rubio, con más de 300 alumnos, que existía antes, como obra del

18 Fernández Soria y López Martín (1991), pp. 35-52; Lull Martí (1997).

19 Comes Iglesia (2009); Sancho de Claver (2014). 
Patronato Obrero y en 1913 superaba los 500 matriculados (Revuelta, 2008, p. 809). El P. Manuel Cadenas fundó las Hijas de Nazaret en Jerez en 1876, en favor de las niñas pobres, y el P. Vicente Ortega inició, también en Jerez, la Asociación de Auxiliares de los Enfermos, en 1896. La congregación de los "Caballeros del Pilar» en Almería financió unas clases nocturnas para chicos trabajadores, extinguidas en $1931^{20}$. Una de las instituciones que sobrevive en la actualidad es la que empezó como Patronato San José para obreros católicos el P. Ramón Hidalgo en Málaga en 1906. Comenzó en una antigua fábrica de jabón en la calle Refino y se trasladó a la espalda de la nueva residencia jesuita, en la calle Pozos Dulces, en $1913^{21}$.

Otra de estas iniciativas fue la Casa del Niño Jesús, de Málaga, fundada por el P. José Manuel Aicardo (Copado, 1943), partiendo de una especie de reformatorio llamado «la perrera» para atender a niños huérfanos de la calle tras la riada de 1907. También se implantó en Andalucía la Asociación San Rafael para protección de emigrantes españoles $(1913)^{22}$.

\subsection{Segunda oleada (1939-1960)}

En la postguerra española, la circunstancia de devastación por la guerra fratricida urgía reconstruir el país y dotarlo de infraestructuras educativas. En este contexto renació la conciencia social en la Iglesia como otro intento de recuperar para la Iglesia a la clase obrera, destinataria, también, incluso privilegiada, del Evangelio. Es lo que llamamos la segunda oleada del apostolado social (Garmendia de Otaola, 1947), muy en línea con la primera oleada. A nivel nacional, los obispos crearon los Apostolados Obreros de Acción Católica: La Hermandad Obrera de Acción Católica (HOAC) en 1946 y la Juventud Obrera Católica (JOC) (1959).

La Compañía de Jesús fue confirmada en este ministerio, cuando la Congregación General 28 (1938) declaró que el trabajo del apostolado social, tal como se deducía de las encíclicas Rerum Novarum (1891) y Quadragesimo Anno (1931), se adecuaba plenamente a la legislación de la Compañía, se contaba entre los ministerios más importantes de nuestra época, y debería promoverse en todas partes. Consideró urgente que se establecieran centros para la investigación y acción social, con una plantilla de jesuitas a plena dedicación y con titulación académica en economía y análisis social. Otros deberían

20 Mañas, (2009), pp. 305-350; Marín Cara, (2010).

21 Soto Artuñedo, (Jábega 2008) pp. 23-35; (2009); (abril 2009) pp. 23-35.

22 Estatutos de la Asociación San Rafael para protección de emigrantes españoles, Imprenta Ibérica E. Maestre, Madrid 1913. 
prepararse para un ministerio social directo entre los pobres, con los campesinos y, especialmente, con los obreros de las fábricas. Este campo incluía desde la atención asistencial, conferencias y Ejercicios Espirituales para obreros, hasta el fomento de asociaciones e instituciones educativas. La Congregación General 29 (1946), añadió que la eficacia en esta clase de trabajo dependería en gran parte de la austeridad de vida de las comunidades jesuitas.

El P. General Jean-Baptiste Janssens escribió una «Instrucción sobre el apostolado social» (1949) ${ }^{23}$ con más eco que los mismos decretos de la congregación. Insistía en que se abriesen Centros de Investigación y Acción Social, "a fin de enseñar la doctrina social en sus aspectos teóricos y prácticos, especialmente a los sacerdotes, los seglares cultos, y a los trabajadores mejor reparados, y para ayudarles con asesoramiento y dirección». Lo más impresionante de la Instrucción es el llamamiento a toda la Compañía a «capacitarse» en aquella caridad activa y sincera que hoy se llama «una actitud social» o «mentalidad social». Por medio de la experiencia el jesuita debería aprender lo que significa pasar toda una vida en circunstancias humildes, pertenecer a las clases más deprimidas de la familia humana, no ser tenido en cuenta y ser despreciado por otros hombres, no poder aparecer en público debido a que uno no tiene ropa decente, ni la preparación social adecuada; ser un mero instrumento por el que otros se enriquecen... y al mismo tiempo contemplar alrededor de uno a aquellos para quienes se trabaja, que abundan en riquezas, disfrutan de comodidades superfluas, entregados a estudios liberales y a las bellas artes, colmados de honores, autoridad y alabanzas.

Los jesuitas crearon en Barcelona la Acción Social y Popular (1939) bajo la dirección del P. Gabriel Palau, y en Madrid continuó Fomento Social iniciado en 1926 como obra del P. Sisinio Nevares (Jiménez Duque, 1979, pp. 457-458). También fomentaron congregaciones marianas obreras, como la que inició el P. Nicolás Puyada en Bilbao en $1946^{24}$. En la primera asamblea nacional, estuvieron presentes jesuitas y congregantes de toda España, si bien en Andalucía interpretaron mal la fecha y solo acudió un congregante de Málaga ${ }^{25}$. Poco después el P. Puyadas enviaba al P. General un programa general nacional de apostolado obrero, con un cierto espíritu de conquista del mundo obrero, y centrado en Barcelona, Madrid y Bilbao, con conexiones nacionales e internacionales. Proponía la creación de una casa de ejercicios para obreros, una escuela de dirigentes, organizaciones sindicales y mutualidades cristianas, cooperativas de consumo y crédito y una gestoría administrativa. Fue desti-

${ }^{23}$ Instrucción del P. Janssens sobre el Apostolado Social, publicada en Promotio Justitiae n.66 (febrero 1997), pp. 23-34.

24 ARSI, Cast 1031 XXIII, 2, Nicolas Puyada al P. General, Bilbao 12.01.1952.

25 ARSI, Cast 1031 XXIII, 2, Primera Asamblea Nacional de Congregaciones Marianas Obreras de España, 29 y 30 diciembre de 1951. 
nado a Venezuela y su sucesor informaba que en realidad la única obra que funcionaba bien eran las cooperativas de consumo y crédito ${ }^{26}$.

En realidad, no será la línea de las congregaciones marianas obreras la que se desarrollará como propia de este tiempo, pues la gran novedad en la postguerra española es la cantidad de escuelas de Formación Profesional que funcionan autónomamente, no como apéndices benéficos e improvisados de los colegios clásicos, sino como centros autónomos, bien equipados y asistidos por una comunidad de jesuitas. Si bien, algunas de ellas surgieron en instalaciones modestas y talleres improvisados, pronto crecieron hasta convertirse en centros politécnicos con toda clase de especialidades. Todo ello, promovido por jesuitas carismáticos sensibles a los obreros y marginados, de los que mencionamos sólo algunos ejemplos: Cristo Rey, en Valladolid (1940), fundado por el P. Antonio Fernández Cid (Díez Menéndez, 2015); el Hogar San José en Gijón, iniciado por el P. Máximo González en 1943 (Roda, 2000); Escuelas Profesionales de Jesús Obrero, en Vitoria, fundado en 1945 por el padre Demetrio Ruiz de Alburuza (Fernández Marco, 1995); la Escuela Profesional Padre Aramburu, en Burgos, del P. Arregui (1945); la Escuela Nazaret de Alicante iniciada por el Francisco Javier Fontova en 1957 (Royo Sánchez, 1996); Escuelas Profesionales San José de Valencia cuyo edificio se inauguró el día 24 de mayo de 1962; el centro Padre Piquer de Madrid (1965) que acogía, como herencia de San José María Rubio, una escuela de 1931; la escuela profesional de Miranda de Ebro, Burgos (1945) (Conde Díaz, 2001) y muchas otras. Todas estas obras nacieron con una clara y visible vocación cristiana.

Los jesuitas españoles asumieron la dirección y docencia de la Universidad Laboral de Gijón desde 1946 hasta 1978, como obra interprovincial, con el objetivo de formar a niños huérfanos de padres víctimas de accidentes laborales en la minería. Para ello se proyectó un edificio que pudiera atender a mil alumnos y que contara con las distintas dependencias requeridas para el desarrollo de la vida estudiantil, como residencia, escuela, talleres industriales, granja, instalaciones deportivas o campos de cultivo (Varios: Gijón, 2008).

En muchas ciudades, la Compañía optó por la periferia, bien como una opción institucional o motivada por opciones personales de personalidades muy influyentes como el P. Llanos, tras su metanoia personal, que lo llevó a instalarse en el Pozo del Tío Raimundo (Madrid) en 1955 (Verdoy, 2005).

Algunos colegios jesuitas de segunda enseñanza sostuvieron también escuelas populares, con el esquema paternalista del momento ${ }^{27}$, pero estos colegios clásicos seguían su ritmo, sin integrar en ellos a estas escuelas populares.

26 ARSI, Cast 1032 V, 4, Carmelo Zubicaray al P. General, Bilbao 30.06.1953.

27 Vila, (1995), pp. 160-162; Carmona (1994); Gómez Caffarena, José, «Catequesis de Entrevías»: Congregación de la Inmaculada para alumnos de $4^{\circ}, 5^{\circ}, 6^{\circ}$ y $7^{\circ}$ de 
Por lo que respecta a Andalucía, podemos clasificar del siguiente modo las instituciones que surgen en esta etapa:

a) Fundamentalmente asistenciales:

- Las congregaciones marianas de Jerez (Varios, 1983), El Puerto de Santa María, y los colegios de Málaga y Sevilla daban de comer a la población hambrienta desde antes de la Guerra Civil.

- El P. José Luis Díez había fundado en Sevilla la congregación mariana de los Javieres, en 1946, para jóvenes, hombres y niños trabajadores, dirigida desde 1948 por el P. Manuel Trenas, que en 1955 fundó la cofradía de los Javieres (Valencia Moreno, 2004). Solía llevar a sus congregantes a zonas marginadas como el asentamiento chabolista del Vacie, de donde surgió la creación del Hogar del Niño Jesús o Ciudad de los Muchachos (Valencia Moreno, 2006 y 2012), para atender a niños huérfanos o sin techo. Comenzó en 1952 en la casa de los Javieres, aneja a la residencia jesuita de la Sevilla calle de Jesús del Gran Poder, y en 1964 se trasladó a los locales de las escuelas de la Gran Madre o Escuelas de la Macarena.

- El P. Bernabé Copado fundó en Málaga en 1945, junto a María Luisa Estrada, la asociación religiosa Siervas de Cristo Abandonado con la finalidad específica de acoger a los niños con problemática familiar y dirigir también allí la Casa del Niño Jesús que había fundado el P. Aicardo. Erigió también la Institución de Cristo Abandonado en 1947 para la formación de jóvenes desamparadas y, creó en Sevilla y Cádiz (1950), otras casas del Niño Jesús para asistencia, crianza y educación de niños huérfanos o con pocos recursos.

b) Fundamentalmente educativas:

- En Sevilla el P. José Cabrera dirigió desde 1936 hasta su muerte en 1953 las Escuelas de la Gran Madre (fundadas por la congregación de madres cristianas) en la Macarena, dependientes de la residencia de Sevilla, que se integrarán en Portaceli, al menos administrativamente, en 1964, antes de que el P. Trenas trasladara a sus locales la Ciudad de

bachillerato (ICAI). Memoria del curso escolar 1940-1941, 55-72; «Bilbao. colegio de Indauchu. Labor social de los alumnos»: Noticias de la Provincia de Castilla Occidental, no 9 (abril 1953) pp. 377-379; Lull Martí (1997), pp. 502-506; Carlos López Pego (1994), pp. 106-124. 
los Muchachos. Funcionaban como escuelas particulares ya que los propios alumnos pagaban a los maestros.

- Hay que tener en cuenta las escuelas promovidas por los «javieres» en Sevilla desde 1951. La congregación de los javieres abrió las Academias San Javier para preparar a jóvenes especialistas. Además, un grupo de centros denominado "Escuelas Católicas San Javier», recibía la dirección espiritual de los javieres: La Inmaculada en la barrio de Nervión; escuela del barrio San Jerónimo; escuela de San Luis, fundada por la antigua Compañía y dirigida por los Hermanos de la Doctrina Cristiana; escuela de Camas; escuela de la calle Betis; escuela de San Clemente; Tiro de Línea; Pasaje Esquivel; Santa Clara; Almonacid; además designaban los profesores para 26 escuelas rurales de Jerez de la Frontera.

- Las gratuitas de Portaceli (Sevilla) iniciadas por el P. Antonio de Luque Peso (curso 1950-1951), que comenzaron con 100 alumnos gratuitos ${ }^{28}$ cuando se inauguró el nuevo edificio en la barriada de Nervión, y llegaron a $200^{29}$. Obtuvieron reconocimiento oficial y las madres de familia mantenían un comedor y ropero para los más necesitados. También se abrió una escuela nocturna en noviembre 1954 que comenzó con 26 jóvenes y llegó a 350; eran obreros entre 15 y 25 años, que recibían clase de 20:00 a 22:00. Por medio de la asociación de padres se les repartió 300 bolsas de comida y 100 mantas $^{30}$.

- El P. Antonio Ciganda, retomando unas escuelas para pobres que tenía el colegio de El Palo dentro de sus instalaciones, al menos desde 1905, inició otra escuela en unas atarazanas en la playa en 1937 que después se convirtió en el Instituto Católico de Estudios Técnicos (ICET) de Málaga, con un buen internado, que fue centro pionero en programas de Formación Profesional antes de su regulación por ley (Soto Artuñedo, 2007). Después se incorporó a la fundación SAFA.

- También se alinea entre estas instituciones la «Escuela Profesional San José» en Málaga, edificada sobre el cimiento del patronato San José, cuya dirección asumió el P. Francisco Mondéjar en 1945.

- La congregación mariana de San Luis en Granada, con ocasión del Cuarto Centenario de la Compañía (1940) reabrió en 1941 un patronato con escuelas nocturnas para adolescentes pobres que ya había

28 ARSI, Pr. Baet. 1009 IX, 13, Informe económico del rector Antonio de Alarcón de 1.01.1952.

29 ARSI, Pr. Baet. 1010 I, 3, Juan M. Ponce al P. General, 3.03.1954.

30 ARSI, Pr. Baet. 1010 VIII, 12, Antonio de Alarcón a Severino Azcona, 22.01.1955. 
funcionado de 1927 a 1932, cuando fue incautado el edificio por el gobierno de la II República.

- En Placeta de Gracia, Granada, abrieron los jesuitas una escuela profesional nocturna en 1944.

- En Granada se constituyó el patronato del Cristo de la Yedra en terrenos del Colegio Máximo de Cartuja en 1960.

- Otra escuela nocturna llamada «Casa Social Católica» se inició en El Puerto de Santa María.

- En 1945 la Compañía asumió la dirección de la enseñanza de la Fundación Carlos Díaz (erigida en Huelva en 1918) formando la «Escuela de Estudios Politécnicos Madre de Dios», gracias a los PP. Antonio Garmendia y José M. ${ }^{a}$ Laraña. Después se incorporó a SAFA (Martínez, 2006).

- En Las Palmas de Gran Canaria: Filial del colegio San Ignacio en El Puerto de la Luz (1954); y una «escuela para pobres» con puerta separada en el Colegio San Ignacio, en Las Palmas de Gran Canaria, (iniciada en 1956). El Patronato de Artesanos (1919) dará lugar a una Escuela Nocturna Obrera (1959-1984) en locales traseros a la Iglesia San Francisco de Borja y la entonces residencia de los jesuitas (Castro Merello, 1992, p. 167).

- En Jerez empezaron las escuelas populares en 196031. Las Escuelas de Cristo Abandonado (Cañameros) de Jerez que había comenzado como una catequesis en la capilla del Cristo de la Yedra en 1924. Esta labor se completaba con una red de escuelas populares apoyadas por jesuitas: Escuelas Madre de Dios, Escuelas del barrio de la Plata, Patronato Nuestra Señora de la Merced.

En este periodo tan prolífico y creativo inician su andadura en la provincia de Jaén las «Escuelas Profesionales de la Sagrada Familia» impulsadas por el P. Rafael Villoslada desde 1939 y diseminadas posteriormente por toda Andalucía $^{32}$. En el curso 2019/20 gestiona 26 centros con casi 28.000 alumnos y algo más de 2000 profesores. Ha recibido diversos reconocimientos en las distintas localidades donde está instaurada y a nivel oficial, además de visitas ilustres, recibió la medalla de Andalucía de 1991.

SAFA se adelantó para poner la educación al servicio del apostolado social, o para hacer de la educación una forma de apostolado social. Se adelantó en ser "factor integrador» del que tratará la CG 32. Supuso una apuesta institucional (si no al principio, al menos a partir de un determinado

31 Provincia de Andalucía (1974), p. 23.

32 Bermudo de la Rosa (1996); VARIOS (2015). 
momento, desde que la Provincia toma el control efectivo de la institución) de opción por el mundo más desfavorecido, que era en la Andalucía profunda de la época (y quizás todavía hoy) el mundo rural.

En nuestra opinión, esta oleada es la que más impacto ha tenido en la historia reciente de España y la que más instituciones ha dejado para la posteridad.

\subsection{TERCERA OLEADA (1960-1995)}

A partir de 1940 se incrementa la conciencia social entre los jesuitas, especialmente entre muchos jóvenes durante los años 50, lo que posibilitará el desarrollo de la misión obrera en las décadas de los sesenta y setenta. Es la tercera oleada de apostolado social, con tintes propios, que convive con las estructuras creadas en las oleadas anteriores.

Entre el comienzo del Vaticano II y la constitución española de 1978 asistimos a una etapa con muchos jesuitas disponibles, especialmente jóvenes sacerdotes, pues aún no dejaba sentir sus efectos la crisis vocacional, apenas iniciada. Pero también fue una época muy crítica, dinámica, incluso convulsa. Hubo un primer periodo de expectación, de demandas de cambios y de gestación de proyectos que corresponden a los años del concilio Vaticano II y la congregación general 31 (1961-66) a los que sucedieron años de reajustes casi vertiginosos (1967-74).

Al doble aggiomamento de la Iglesia y de la Compañía subyacía, especialmente en la España del tardofranquismo, el intensísimo terremoto sociocultural (con su epicentro en el mítico mayo del 68 francés), que los sociólogos denominan proceso de modernización (años sesenta-noventa) y sus consecuencias en la Iglesia, cuya renovación había iniciado Juan XXIII convocando el concilio Vaticano II.

El promotor de esa renovación de la Compañía de Jesús fue el padre Pedro Arrupe, elegido prepósito general en 1965. Un hito en este proceso fue la congregación general 32 (1974-75), especialmente su decreto $4^{\circ}$ "Nuestra misión hoy: el servicio de la fe y la promoción de la justicia», que reformulaba aquellas dos vertientes de la Fórmula del Instituto como líneas prioritarias para la Compañía en el futuro: «el servicio de la fe, del que la promoción de la justicia constituye una exigencia absoluta» ${ }^{33}$. La CG 32 supone un doble giro radical, que afecta directamente a lo que se entendía por «apostolado social»:

33 Congregación General XXXII de la Compañía de Jesús de 1975. Ver, por ejemplo: Peter-Hans Kolvenbach (2000). «El servicio de la fe y la promoción de la justicia en la educación universitaria de la Compañía de Jesús de Estados Unidos». 
- La justicia no se entiende solo en el ámbito interpersonal (atención a los obreros), sino fundamentalmente en el ámbito estructural. No se limita a paliar los efectos de la injusticia, sino que busca las causas de esta y sus posibles remedios. Esto no es exclusivo de la Compañía, pero responde a una nueva manera de enfocar los problemas sociales y es esencial para ver (y valorar) lo que se hace antes y después de ese momento.

- La transversalidad de esa formulación de la misión. La CG 32 habla de «factor integrador» de todos nuestros ministerios y actividades. Esto cuestiona de raíz todo lo que hacíamos antes y abre nuevas vías de acción en campos tan importantes como la educación o las parroquias, por hablar de dos actividades muy diferentes entre sí. Pero esto afecta también a las comunidades, de donde se puede explicar la proliferación de comunidades de inserción, sean de misión obrera o no. En todo caso, este es un enfoque muy característico de la Compañía, a diferencia del anterior.

Este programa, dinamizado por el concilio Vaticano II (1962-65) y liderado por el P. Arrupe es el que constituye la renovación de la Compañía de Jesús ${ }^{34}$. En Valencia en 1973 el P. Arrupe interpeló valientemente a los Antiguos Alumnos: "¿Os hemos educado para la justicia?" para responder "con toda humildad que no; que no os hemos educado para la justicia»" ${ }^{35}$ Su sucesor, el P. Peter-Hans Kolvenbach comentando esa cita de Arrupe, dice que «el cuestionamiento del P. Arrupe sigue sacudiéndonos hoy ${ }^{36}$. En ese mismo contexto, hablando de la educación y la justicia alumbró la feliz fórmula de que el objetivo de los colegios de la Compañía era educar «hombres [y mujeres] para los demás» ${ }^{37}$.

Al mismo tiempo, el P. Arrupe concedió al sector social un espacio dentro de la curia general, cuando estableció el Secretariado para el Desarrollo Socio-Económico (JESEDES), nombrando responsable de él a su consejero, el P. Francisco Ivern. De aquí surgió en 1969 el Secretariado para la Justicia Social. Sus funciones incluían la promoción de obras socioeconómicas y estudios de campo; fomentar el contacto e intercambio de información entre

\footnotetext{
34 Ver, por ejemplo, Valero Agúndez (2012); La Bella (2019).

35 «La promoción de la justicia y la formación de las Asociaciones de A.A.» Información SJ 27 (1973), 230; Revuelta González, 2006, pp. 213-229.

36 Vídeo-mensaje del P. Peter-Hans Kolvenbach, Superior General de la Compañía de Jesús al Congreso de la Confederación Europea de Antiguos Alumnos de la Compañía, Malta, 1-3 de noviembre de 2001.

37 http://www.sjweb.info/documents/education/arr_men_sp.pdf
} 
los centros sociales de la Compañía; asegurar una presencia activa jesuita y eclesial en los congresos y asociaciones internacionales interesados en el desarrollo, etc.

En Andalucía, en este periodo se forjaron instituciones de gran calado social, como la Escuela Superior de Técnica Empresarial Agrícola (ETEA) (Varios, 2014) que comenzó en 1963, germen de la Universidad Loyola Andalucía (2010). ETEA nace casi 20 años después que SAFA, pero con una orientación parecida: favorecer el desarrollo de una Andalucía tradicionalmente atrasada. Por eso acentuó en sus orígenes la orientación rural (Escuela Técnica Empresarial Agrícola). En aquellos primeros años, dedicó muchos recursos a la investigación buscando la promoción del campo andaluz. Y luego se orientó muy decididamente a la cooperación al desarrollo, ya en los años 1980, creando un servicio específico para esta área que promovía los proyectos de cooperación y la colaboración de profesores in situ. Esta línea fue tan relevante que la misma Administración Pública sugirió crear una fundación para encauzar esta actividad y darle una mayor visibilidad. Hoy, desarrollo y cooperación son líneas prioritarias de actuación asumidas por la Universidad Loyola Andalucía, consciente de que esto no es una decisión tomada desde cero, sino para recoger, aprovechar y potenciar una tradición que se remonta a los orígenes de ETEA.

Como fruto de esta sensibilidad, algunos jesuitas dejaron sus viviendas de estilo semi-conventual, y, buscando una mayor inserción entre los obreros, se trasladaron a vivir en los suburbios pobres de las ciudades o a comunidades de campesinos, y experimentaron las consecuencias duras y diarias de las injusticias y de la opresión. De este encuentro surgieron compromisos relacionados con la vivienda, atención sanitaria de primera necesidad, educación básica, reforma agraria, creación de empleo, derechos humanos, derechos civiles, participación, promoción del cambio (advocacy) y otros muchos, todos ellos iban dirigidos a la transformación de las estructuras en busca de la liberación tanto espiritual como material del hombre.

Parte de este movimiento es la Misión Obrera ${ }^{38}$, a la que podemos considerar el exponente más claro de esta tercera oleada del apostolado social. Supuso otro acercamiento al mundo de los desfavorecidos, aunque con pretensiones distintas a las anteriores. Las oleadas de finales del siglo XIX y posguerra, tenían muy clara la visibilidad y el objetivo evangelizador directo o catequético, junto con la asistencia social y la promoción social a través de la formación. Ahora se buscaba más la inserción, el ser fermento,

38 Ver, por ejemplo: Centeno (2008); Corrales (2008); Hurtado Sánchez (2009), pp. 351-372; Rodríguez Molina (2009). 
con poca visibilidad, en condiciones lo más similares posibles a los obreros, para participar de la dura vida de los trabajadores y promover la concientización y la transformación estructural de esas condiciones.

Así, pues, un grupo cambiante de jesuitas de Granada fue a vivir a barriadas como Santa Juliana (1967-19), la Encina-Frigoríficos (1969-73), La Virgencica (1971-74), Zaidín-Bailén (1967-83), Zaidín-Torremocha (196872) y Almanjáyar (desde 1983). No sólo buscaban un mayor acercamiento a los desfavorecidos, sino compartir la vida con ellos, incluido el trabajo como curas obreros. Hubo un acercamiento al mundo gitano especialmente en Granada, como el del catalán Pedro Closa (Renau Manén, 2003) (193271), o el de Adolfo Chércoles ${ }^{39}$ como cura obrero entre gitanos o Ignacio Molina que pondrá en marcha iniciativas educativas como una Autoescuela y la Escuela de Adultos Los Bolines en $1981^{40}$.

En Sevilla se inició un grupo de curas obreros en el Cerro del Águila (1967-80), así como en Huelva, en la barriada del Carmen (1968-71). También hubo un coetus en el ambiente rural cordobés, de Fuente Palmera, (1972-79) y Fuente Carreteros (1979-84), donde se asumieron tres parroquias en 1972. Otro grupo de jesuitas fue destinado en 1976 a trabajar en una comunidad de inserción en la calle Palmar del barrio de La Isleta (Las Palmas), trasladándose después a la calle Los Pinzones, y finalmente hacia 1987 a Los Claveles.

En un trabajo inédito, Ignacio Molina computa un total de 35 jesuitas con trabajo manual prioritario (incluyendo oficios como maestro o taxista), y otros 15 con algún trabajo manual, en la provincia Bética.

Esta realidad que acabó llamándose apostolado social también recibió un grado de institucionalización, juntamente con los distintos sectores apostólicos de la provincia Bética, aunque no siempre con el mismo nivel. Así, se creó una figura que puede ser considerada como bisagra de la segunda y tercera oleada que fue encarnada por Manuel Bermudo. Es la figura del promotor del apostolado entre obreros, tal como aparece en el catálogo de 1965, una vez que acabó su primer rectorado de SAFA. A partir de 1968, cuando empezaba su segundo rectorado, es nombrado consultor de provincia, lo que indica el valor que se le concedía a su misión. Igualmente, en 1970, Gonzalo Sánchez Romero (un histórico de la misión obrera granadina, que comenzó en Sevilla y entonces era profesor de la Escuela Universitaria Padre Manjón) figura entre los secretariados sectoriales como subsecretario de apostolado entre trabajadores.

39 https://www.acheesil.com/adolfo-chercoles/

40 https://studylib.es/doc/135190/escuela-de-adultos-los-bolines 
Los jesuitas más admirados por los jóvenes en formación eran los que trabajaban en la brecha de la acción social. También se produjeron ciertas disfunciones, pues al enfatizar un aspecto de la misión (la social), parecía que se desvalorizaba o despreciaba el resto (educativa y pastoral) lo que produjo cierta fricción con el resto de jesuitas, especialmente con los superiores, ya que los ministerios tradicionales se sintieron amenazados. En los colegios clásicos, esto coincidió con una profunda crisis de identidad en los años setenta, con la excepción de SAFA que siempre estuvo bien valorada entre los jesuitas andaluces.

Algunos jesuitas asumieron postulados marxistas y compromisos políticos y sindicales con esta orientación, lo que acabó creando problemas de compatibilidad y enfrentamiento con otros jesuitas y los superiores, como ocurrió con Horacio Lara, dimitido de la Compañía en 1977 por su militancia en el partido comunista, si bien la de Llanos fue tolerada, así como colaboraciones con otros partidos como la Unión de Centro Democrático, aunque sin una clara militancia. Para colmo, la crisis socio-religiosa y vocacional provocó muchos abandonos en todos los sectores, pero se prodigaron más en esta misión ( 21 de 35 , es decir, el $60 \%)^{41}$, quizás por estar más a la intemperie, y, quizás, por cierta debilidad en el cultivo de la dimensión religiosoespiritual, por lo que las mismas comunidades de misión obrera acabaron por ser insostenibles. Algunos núcleos desaparecieron, y otros se diluyeron en núcleos comunitarios más amplios, de modo que la misión obrera dejó de ser exclusivamente lugar de residencia de jesuitas que realizaban trabajos por cuenta ajena, muchas veces manuales, para incluir a otros jesuitas en trabajos intelectuales o pastorales con una determinada sensibilidad.

Algunos consiguen infundir a sus ministerios aquella fe reformulada en contacto con los trabajadores, como realiza Adolfo Chércoles en su ministerio de los Ejercicios Espirituales, a quien podemos llamar con justicia, el último trabajador manual de la misión obrera jesuita andaluza, pues ha sido el único jesuita andaluz, que se ha jubilado trabajando manualmente. Motivado por su deseo de estar con los últimos, marchó a Paraguay con los guaraníes (1975-77), donde, en una convalecencia con la pierna dañada por un accidente (algo con muchas resonancias entre los jesuitas...) cayó en sus manos el libro de Gaston Fessard, La Dialectique des "Exercices spirituels" de saint Ignace de Loyola (3 vol.), 1956-84 ${ }^{42}$. Con su lectura y estudio redescubrió

${ }^{41}$ Datos tomados de un trabajo inédito de Ignacio Molina, que ha realizado una buena recopilación de datos estadísticos y ha realizado entrevistas a muchos de los protagonistas, pero que está a falta de sistematizar un poco ese material y publicarlo.

42 El volumen 1 (Temps-liberté-grace) y el 2 (Fondement-Pêchê-Orthodoxie) fueron publicados por Aubier 1956-1957. Un tercer tomo póstumo, Fessard había muerto en 1978 (Symbolisme et historicité) fue editado en 1984 por Éditions Lethielleux. 
y comprendió mejor la espiritualidad ignaciana y las bienaventuranzas, y se ha convertido en un referente en la materia, cuya orientación, además de influjos personales, ha creado escuela, con la «Asociación Adolfo Chércoles» dedicada a los Ejercicios Espirituales ${ }^{43}$.

Aunque no en la órbita de la misión obrera, pero sí motivadas también por una cierta sensibilidad hacia los marginados, se asumieron parroquias de barriada como plataformas de evangelización y de acción social, como la Pilarica en Valladolid (Varios, 2007) o Nuestra Señora de Belén en Zaragoza (Varios: Zaragoza, 2015). En el barrio de La Jota (Zaragoza) se inició hace más de 30 años una experiencia de dos jesuitas (José Luis Ochoa, qué fue Coordinador Nacional de Misión Obrera) y el hermano Demetrio Morato, en convivencia con un grupo de laicos, mayores y jóvenes en familia, permitido por la Compañía «ad experimentum». La casa está abierta a huéspedes amigos, con labores también en barrio y vecinos.

En la provincia Bética también se asumieron parroquias marginales como Nuestra Señora de las Veredas, en la barriada de Valdezorras, Sevilla (1968-1986), y San Antonio de Padua e Inmaculado Corazón de María, en el barrio de Torreblanca, Sevilla (desde 1981). Además, algunas residencias se trasladaron a la periferia: la de Jerez de la Frontera, a la parroquia Madre de Dios que ya atendía desde 1967, con un coetus (1969) y como coetus principal (1970). Desde ella se atendía la de San José (1969-2011). La del centro de Almería se trasladó a la barriada marginal Piedras Redondas, para hacerse cargo de las parroquias de San Ignacio, Nuestra Señora de Araceli y El Buen Pastor (1982), esta última, en un enclave gitano. Otra iniciativa personal fue la de Juan Fernández Marín que creó una asociación de obreros en Cádiz y Málaga, a modo de una congregación mariana, pero que murió con él.

Igualmente, surgen en este periodo otro modo de estar en la sociedad que suponían las emisoras de radio, con un fuerte impacto popular: una emisora en Sevilla y las dos de Radio Popular Jaén y Granada (1967). También en este campo se asumió la educación de gente marginada culturalmente a través de la emisora de Montilla (1961, trasladada después a Córdoba), dedicada a la alfabetización y radiodifusión cultural y religiosa. El P. Francisco Villén, entonces jesuita, pasó de Córdoba a las Islas Canarias, llevando la radio enseñanza, y fundó Radio ECCA (Emisora Cultural Canaria) en $1964^{44}$.

43 https://www.acheesil.com/adolfo-chercoles/

44 Varios (1976); López Pérez (2005). 


\subsection{Cuarta OlEAdA (DESDE 1995)}

A partir de 1995 la Compañía se reafirma en su dimensión social, renovándola. Habían pasado más de 20 años del decreto $4^{\circ}$ de la CG 32, pero en 1995, la Congregación General 34 reafirmó vigorosamente la misión única de la Compañía que consiste en la evangelización, sirviendo a la fe y promoviendo la justicia del Evangelio, que encarna el amor y la misericordia salvadora de Dios, en diálogo con las culturas y las religiones. En efecto, la congregación declaro que el decreto $4^{\circ}$ de la CG 32 correctamente entendido, constituye nuestra 'misión posible', para toda la Compañía en común. Posteriormente se celebró un Congreso internacional, en Nápoles en junio de 1997, cuyo tema fue: llevar la justicia del Evangelio a la sociedad y a la cultura. Los 160 delegados reconocieron las complejidades del cambio sociocultural-religioso y, con realismo y esperanza, aceptaron gozosamente las dificultades. Se elaboró un catálogo con información detallada, provincia por provincia, de lo que los jesuitas estaban realizando en el sector social y en la dimensión social de otros sectores.

El instrumento de renovación más importante de esta etapa es el documento Características del Apostolado Social de la Compañía de Jesús, publicado como borrador de trabajo en 1998 (Promotio Iustitiae 69, 1998). Este nuevo texto transmite las preocupaciones esenciales, los enfoques y las convicciones típicas, las preguntas que no pueden dejar de ser planteadas y las tensiones que hay que mantener, la muy deseable pero huidiza colaboración mutua entre «cabeza» $\mathrm{y}$ «pies».

Una vez que la provincia Bética se había integrado en la provincia de España en 2014, la congregación general 36 (2018) asumió todo lo anterior, poniendo el énfasis en la ecología y el cuidado de la casa común, en consonancia con la encíclica Laudato si' (2015), del papa Francisco, algo que ya estaba en el decreto 3 de la C.G. 35 (2008), en el esquema de la reconciliación a tres niveles: con Dios, con la humanidad y con el cosmos. Un momento importante de autoafirmación y reforzamiento del apostolado social en la Compañía fue el congreso mundial celebrado en Roma con motivo de los 50 años del Secretariado para la Justicia Social y la Ecología en noviembre de noviembre de 2019, pocos días después del importante Sínodo sobre la Amazonía.

En este periodo un amplio abanico de actividades y campos cobran fuerza, si bien su implantación en la provincia Bética es desigual: Servicio Jesuita a Refugiados (establecido en 1980 por el P. Arrupe), Servicio Jesuita a Migrantes, campañas y actividades de advocacy, trabajos en diversas ONG como Entreculturas, reflexión en los centros Fe-Cultura-Justicia-Ecología, 
comunidades de inserción y acogida. Entreculturas nació para dar cauce a la oficina que tenía el P. García del Cerro en Madrid, cuyo objetivo era apoyar a Fe y Alegría, una red de escuelas creada en Venezuela y luego extendida a todo el continente para educación de las clases populares, como SAFA. Por eso Entreculturas no es una ONG para todo, sino que se centra especialmente en la educación de los colectivos más desfavorecidos.

Algunas de las características de esta etapa son el trabajo en redes internacionales y la misión compartida con no jesuitas. Se puede decir que el espíritu del sector social ha entrado en los otros sectores manteniéndose una fluida colaboración entre ellos, superando los recelos de los años setenta.

Por lo que respecta a la provincia Bética, cuando se empieza a pergeñar una nueva estructura de gobierno, en 1973, se crearon comisiones para los ámbitos apostólicos, y es interesante que, junto con la comisión de formación, educación y pastoral, se iniciara otra de Fe-Justicia-Cultura, a pesar de que tenía bastante menos peso institucional y realidades pastorales que las anteriores, lo que es toda una línea programática. No obstante, esta declaración de intención parece parcial y no equiparó el sector de apostolado social a los otros clásicos, pues si bien se nombraron delegados del provincial para la formación, educación y pastoral, en el caso del apostolado social no llegó el nombramiento hasta 2001, en que lo recibió José Juan Romero, con gran prestigio en toda la provincia. Le sucedió José Luis Soto en 2003 y Fernando Motas en 2006. En 2008 asumió esta función un laico, la primera vez que un laico era nombrado delegado sectorial del provincial: Eduardo Ibáñez Ruiz del Portal. Esta figura facilitó un mayor grado de institucionalización del apostolado social, lo que redundó en una mayor visibilización y coordinación así como la colaboración con los otros sectores, especialmente, el educativo.

Los colegios agradecieron esta colaboración con el sector social que les ayudó a sensibilizar a los propios alumnos, por ejemplo, a través de Entreculturas. Pero, además, bastantes colegios se habían convertido en otro tipo de agentes sociales. Hasta ahora las escuelas profesionales formaban a los hijos de trabajadores en estudios profesionales, pero con la enseñanza comprehensiva decretada por la LOGSE (1990) para la escolaridad obligatoria, estos centros educativos habían dejado de ser centros exclusivos de formación profesional para acoger alumnos de todos los niveles educativos no universitarios. Esto, junto con la legislación para la admisión de alumnos de centros concertados promovió una cierta renovación del perfil de alumnos de los colegios clásicos jesuitas, haciéndolo menos exclusivo. En los Centros antiguos de formación profesional también produjo un cambio sociológico del alumnado, que ya estudiaban también bachillerato. En algunos centros, especialmente de SAFA, por la zona en la que están insertos, 
se produjo una avalancha de hijos de inmigrantes, lo que los convierte en centros interculturales. También en este campo se ha producido una colaboración intersectorial.

Institucionalmente, en los últimos años el apostolado social en la provincia Bética se ha ido especializando en tres áreas, igual que el resto de las provincias españolas, lo que facilitó la integración de todas en una sola provincia en 2014:

- Ayuda a la cooperación internacional. En la provincia Bética se ha realizado fundamentalmente, con las ONG Entreculturas ${ }^{45}$, con sede en todas las provincias andaluzas, y la Fundación ETEA para el Desarrollo y la Cooperación ${ }^{46}$.

- Migraciones. A nivel nacional se ha creado el Servicio Jesuita para Migrantes, (SJM), pero en la provincia Bética tiene más presencia la asociación Voluntariado Claver $^{47}$, además de la actividad de muchos centros SAFA. La comunidad de Almería convive con colectivos de inmigrantes a los que acompaña, especialmente con la colaboración con Almería Acoge. Además, a nivel personal los jesuitas colaboran o han colaborado con ONG para atender a emigrantes como Andalucía Acoge.

- Menores y jóvenes en riesgo de exclusión social. Además de los centros educativos, especialmente SAFA, hay algunas iniciativas. La fundación jesuita cordobesa Hermida de la Chica, fundada por Jaime Loring, colabora en con la asociación Arco Iris en la rehabilitación de drogodependientes. Otra asociación cordobesa, P. Morales, animada por el jesuita Vicente Theotonio, mientras vivió, ha dedicado sus esfuerzos en favor de la población marginada, rehabilitando la Casa «Emaús» en Trassierra, colaborando con «Arco Iris» y propiciando una Escuela Gitana de Educación de Adultos en el Barrio de los Vikingos. También los jesuitas han colaborado con Proyecto Hombre, especialmente en Málaga y Sevilla.

Otras iniciativas que sirven a las dos últimas áreas son: el comedor infantil en la parroquia de San Antonio, Torreblanca, Sevilla, iniciado en 1987 y otro en la otra parroquia del Inmaculado Corazón de María, también en Sevilla. En Huelva una asociación creada por el P. Gerardo Bravo en 1983 mantiene el comedor social «Virgen de la Cinta» en un edificio cedido por la Compañía. En 2013 se puso en marcha una cocina autogestionada en la

$45 \mathrm{http}: / /$ www.entreculturas.org/index.php

46 http://www.fundacionetea.org/

47 http://www.voluntariadoclaver.org/ 
parroquia Madre de Dios (Jerez). Otras iniciativas más personales se debieron a jesuitas sensibles con los pobres: En Málaga el P. Enrique Huelin creó la «Asociación Benéfica Padre Huelin», cuya gestión heredó su sobrino, también jesuita, Carlos Huelin. También el carismático P. Jorge Lamothe puso en marcha una iniciativa que murió con él, la «Casita de San José» para los sintecho, iniciada en 1997 (Soto Artuñedo, 2006).

Últimamente se han reutilizado algunos domicilios de comunidades jesuitas clausuradas para usos sociales. Así, los pisos del Teologado de Granada en Paseo de Cartuja, 19, se cedieron en 2007 a Cáritas diocesana para pisos de acogida. Una última iniciativa en Andalucía puesta en marcha en 2019 ha sido utilizar los pisos de la clausurada comunidad de ETEA en Córdoba para la casa Claver-Córdoba, un proyecto de Hospitalidad, en red con la fundación EMET-Arco iris (proyecto Ödos), que acoge a mujeres migrantes que necesitan un apoyo temporal en su paso por España hacia otros países de destino.

Una obra insólita relacionada con la Compañía de Jesús es la residencia de tercera edad San Rafael, de Dos Hermanas, fundada por el jesuita José M. ${ }^{a}$ Mier-Terán (Mier-Terán, 2004) con la colaboración de la Compañía de Jesús, el Círculo Tarso y su familia, inaugurada por Juan Pablo II en 1993. Era gestionada por la Fundación Social San Rafael, cuyos principales componentes eran jesuitas o miembros de la familia Benjumea (Hoyo y Escriña, 2003).

El Magreb ha sido siempre ese vecino con quien se vive dándose la espalda, fuera de algunos ministerios en Ceuta y Melilla. El P. Antonio Pascual Martín, finalizada su misión educativa en Málaga, dedicó su vida a acompañar a las reducidas comunidades católicas del Atlas y a la gente local, a quién asistía en lo que podía con las ayudas que recibía, por lo que mereció ser llamado «Padre de los pobres». Su muerte en 2005 fue muy sentida ${ }^{48}$.

Recientemente se ha establecido un coetus más estable en Nador (Marruecos). Se debe a la iniciativa del creativo histórico de Misión Obrera, Esteban Velázquez Guerra, que, desde 1993 está interesado en iniciativas que tienen que ver con la solidaridad con el tercer mundo, la interculturalidad y el diálogo interreligioso. Así promovió «Encuentro de caminantes» (200207), la Iniciativa "Cambio personal, justicia global», y el proyecto "Casa de las Culturas»(2007-12). En 2012 aceptó una colaboración con la diócesis de Tánger y se trasladó a Nador donde asumió las siguientes tareas: Dirección del Centro de Formación Profesional y Cultural Baraka, Delegación diocesana de Migraciones (con la acumulación de emigrantes subsaharianos en el monte Gurugú), Formación espiritual e interreligiosa, al tiempo que continuaba promoviendo la «Iniciativa por el cambio personal y la justicia

48 Cfr. Gouin. 
global». Pero injustificadamente fue declarado persona non grata en 2016, sin ofrecerle motivos ni ser oído, por lo que no pudo regresar en Marruecos. Actualmente atiende esos trabajos la pequeña comunidad «Beato Luc Dochier», dependiente de la comunidad de Almería, de la provincia de España, si bien es territorio de la de Próximo Oriente.

Desde la creación de la única provincia de España en 2014, se mantienen estas líneas de acción, ahora con una mayor coordinación y colaboración entre todas las instituciones del Estado, bajo el liderazgo de un laico como delegado provincial del sector de Apostolado Social, Luis Arancibia.

\section{CONCLUSIONES}

1. La preocupación por los pobres siempre ha estado presente en la Compañía, desde su inicio, en los documentos fundacionales y en la práctica de los jesuitas. No obstante, ha prevalecido la imagen de la Compañía como educadora y evangelizadora de los ricos, al menos en la antigua Compañía.

2. Esta preocupación se ha expresado con distintas fórmulas según los tiempos. Al comienzo eran más asistenciales, y esta dimensión se ha mantenido a lo largo del tiempo. Pero han ido ganando terrero las iniciativas educativas, y más recientemente, las que pretenden promover la conciencia social y la transformación de estructuras.

3. Hemos recogido realidades de muy diverso calado que no deben homogeneizarse: Hay iniciativas de un jesuita que mueren con él; otras perduraron, aunque fueron obra de un jesuita (algunas sin mucho apoyo institucional); hay iniciativas institucionales...Incluso obedecen a concepciones muy diferentes de la sociedad, el apostolado, la forma de entender la misión de la Iglesia y la Compañía o el carácter presbiteral de la Compañía.

4. Esto nos lleva a preguntarnos por el concepto de "apostolado social». Evidentemente dentro de esa denominación han entrado cosas muy diferentes que han ido evolucionando con el paso del tiempo, en un proceso no exclusivo de la provincia Bética. Se ha pasado de la atención social de los pobres a una implicación personal y comunitaria en línea con la CG 32.

5. Quizás la actividad más constante en todas las etapas es la educación, campo en el que los jesuitas pueden ser considerados maestros experimentados. De hecho, la educación, entendida como desarrollo de las potencialidades personales, tarde o temprano produce efectos revolucionarios, aunque el desarrollo de las potencialidades signifique al principio una mera 
alfabetización, pues desde ahí es posible promover una forma distinta de percibir y comprender el mundo para cambiarlo.

6. En la Historia contemporánea de la Compañía de Jesús en España se pueden establecer cuatro oleadas o momentos de especial llamada a trabajar entre los pobres. Cada una de estas oleadas aporta su propia impronta. La primera pretendía la catequización del mundo obrero a través de iniciativas culturales; la segunda, la promoción profesional de los desfavorecidos; la tercera pretendió ser fermento trabajando codo con codo con los trabajadores; la cuarta actúa en perspectiva más global y estructurada.

7. Muchas acciones en favor de los necesitados comienzan como iniciativa personal de jesuitas sensibles a los pobres, que pasan de dar limosna a organizar algo más estructurado, pero sólo han pervivido las obras que, de algún modo, son asumidas institucionalmente por la Compañía, por ejemplo, la red de centros SAFA, la escuela San José (Málaga) o el ICET (Málaga).

8. Respecto de la misión obrera, las oleadas anteriores dejaron como testigos infinidad de instituciones educativas y sociales, pero los jesuitas de la misión obrera no pretendían crear obras, sino fundirse con la masa obrera y trabajar en medio de los obreros, por lo que su herencia no es tan evidente. En algunos casos, el compromiso vital los abocó a asumir compromisos políticos y sindicales, ya sea con la militancia o con la asunción de cargos, con lo que también se beneficiaron de estos operarios los partidos políticos y sindicatos. Por lo que respecta a la Iglesia, se produjo un cambio de mentalidad importante en los protagonistas, de manera que su espiritualidad y su teología ya no serían como antes, e intentaron un cambio similar en las estructuras eclesiales, con diversa fortuna.

Es muy fuerte el vínculo entre los jesuitas, sacerdotes, religiosas, laicas y laicos que integraron la misión obrera, que cada año, desde 1995, celebran un retiro anual en el Pirineo y otro en Zaragoza.

9. La provincia Bética tiene dos aportaciones muy significativas: SAFA y ETEA (incluida la Fundación ETEA). Estas dos obras ponen de manifiesto cómo la dimensión estructural de la justicia se convierte en factor que modifica un apostolado tan tradicional en la Compañía como es la educación. SAFA se adelantó claramente en el tiempo. ETEA nació cuando esta preocupación iba anidando en muchos jesuitas preocupados por el apostolado social pero que buscaban formas alternativas a las que en aquellos años 1960 parecían imponerse, que era la misión obrera y las comunidades de inserción (un término este que se ha generalizado luego, pero que entonces no se usaba).

10. Queda por estudiar el impacto social de una institución de iniciativa personal pero asumida desde el principio por la provincia Bética, como es 
la SAFA. Sería interesante estudiar el influjo de SAFA en la región andaluza, por su contribución al desarrollo cultural y profesional de sectores desfavorecidos de la población, y la función que en ello han tenido tantas generaciones de maestros formados en Úbeda, cuya mayor parte era oriunda de la provincia de Jaén. También sería digno de estudio su contribución al cambio de mentalidad en los propios jesuitas, como aglutinante institucional de una nueva identidad apostólica y promotor de una nueva sensibilidad entre los jesuitas andaluces. También sería útil un estudio del impacto social y económico de ETEA, en qué medida ha contribuido a modificar la estructura productiva y económica del campo andaluz.

\section{REFERENCIAS}

Aldama, A.M. ${ }^{a}$ de, et. al. (1997). La fórmula dell'Istituto S. J. Roma: IHSI.

Aldea, Q., Martín Tejedor, J. y García Granda, J. (Eds.) (1987). Iglesia y Sociedad en la España del siglo XX. Catolicismo Social, Tomo II. 1918-1920, Madrid: CSIC, 680-694.

Álvarez de los Mozos, P. (2018). Servir a los pobres, promover la justicia. Panorámica histórica del apostolado social de la Compañía de Jesús. Bilbao: Mensajero.

Andrés-Gallego, J. (1997). La labor formativa del catolicismo social. En B. Bartolomé Martínez (Dir), Historia de la acción educadora de la Iglesia en España II. Edad contemporánea, Madrid: BAC, 835-867.

Arranz Roa, Í. (2004). La atención a pobres y menesterosos en la Provincia de Castilla de la Compañía de Jesús 1550-1650, tesis doctoral leída en la Universidad Pontifica de Comillas para la obtención del grado de doctor, bajo la dirección del Dr. Revuelta González, Madrid.

Bermudo de la Rosa, M. (1996). SAFA, medio siglo de educación popular en Andalucía. Historia de las Escuelas Profesionales de la Sagrada Familia, 1940-1990. Jaén: Universidad de Jaén / Octaedro.

Camacho, I. (1984). La Encíclica 'Rerum Novarum', su proceso de elaboración a través de los sucesivos textos preparatorios. Granada: Facultad de Teología.

Camacho, I. (1986). La Chiesa di fronte al liberalismo e al socialismo. Per una interpretazione più completa della Rerum novarum. Civiltà Cattolica 137/1, 219-233.

Carmona, F. J. (1994). La Compañía de Jesús y el liderazgo católico en la Barcelona de los cuarenta. Granada: Universidad.

Castillo, J. J. (1976). Modulaciones ideológicas del catolicismo social en España: de los Círculos a los Sindicatos. Revista Española de la Opinión Pública, 45, 37-75;

Castro Merello, A. (1992). Colegio San Ignacio de Loyola. Las Palmas de Gran Canaria: Colegio San Ignacio.

Centeno, J. (coord.) (2008). Curas obreros, 45 años de testimonio 1963-2008. Madrid: Herder.

Churruca Peláez, A. (1999). La Compañia de Jesús ¿cómo nació? México: Buena Prensa. 
Comes Iglesia, V. (dir.) (2009). Cuidados y consuelos. Cien años de Fontilles. Valencia: Generalitat.

Conde Díaz, C. (2001). Los Jesuitas en Miranda de Ebro. Estudios mirandeses: Anuario de la Fundación Cultural "Profesor Cantera Burgos», 21, 44-60.

Congregación General XXXII de la Compañía de Jesús. Razón y Fe, Madrid 1975, 69-100.

Copado, B. (1943). Al margen del camino. Notas biográficas del P. José M. Aicardo. Málaga: Urania.

Corral, J. (1998). El Padre Bernardino de Antequera, los fundadores de la Hermandad del Refugio y Piedad de esta corte y el Madrid de su época. Madrid: Hermandad del Refugio.

Corrales, X. (2008). De la misa al tajo. Valencia: Universidad.

Czerny, M y Foglizzo, P. (2008). El Apostolado Social en el siglo XX. En F. Ivern, SJ et. al. Recordando nuestra Historia. Roma: SJES.

Díez Menéndez, C. (2015). Cristo Rey: 75 años de servicio. Bilbao: Mensajero.

Fernández Marco, J. I. (1995). Jesuitas en Vitoria. Año Cincuentenario de «Jesús Obrero». Vitoria: Caja Vital Kutxa-Fundación Jesús Obrero Vitoria.

Fernández Soria, J. M. y López Martín, R. (1991). «Los colegios jesuíticos valencianos: datos para su historia». En R. Calatayud Soler y otros, Cuestiones históricoeducativas. España. Siglos XVIII-XX. Valencia: Universidad.

García Granda, J. (1990). Iglesia y sociedad en la España del siglo XX (El P. Sisinio Nevares y el catolicismo social). Madrid: Razón y Fe.

García Hernán, E. (2007). Archivum Historicum societatis Iesu. 76, 177-180.

García Nieto, J. N. (1960). El sindicalismo cristiano en España. Bilbao: Universidad de Deusto.

Garmendia de Otaola, A. (1947). Jesuitas y obreros. Bilbao: Artes Gráficas Grijelmo.

Gouin, F. (Compilador). [s.f]. Padre de los pobres Antonio Pascual Martín, S.J. Párroco de Midelt (Marruecos) 1989-2005. Testimonios, traducción española por Rafael Yuste Moyano. Midelt (Marruecos): Asociación AMAD.

Hoyo, J. del y Escriñá, J. M. (2003). Javier Benjumea Puigcerver (1915-2001). Primer marqués de Puebla de Cazalla. Madrid: Gráficas Lope.

Hurtado Sánchez, J. (2009). Curas y obreros contra la dictadura franquista. Anuario de Historia de la Iglesia andaluza, 2, 351-372.

Jiménez Duque, B. (1979). Espiritualidad y Apostolado. En R. García Villoslada (dir), Historia de la Iglesia en España, Vol. 5 (La Iglesia en la España Contemporánea. 1979), dirigido por V. Cárcel Ortí. Madrid: BAC 395-474.

Jiménez Oñate, A. (1966). El origen de la Compañía de Jesús. Carisma fundacional y génesis histórica. Roma: IHSI.

Kolvenbach, P.-H. (2003). La Compañía de Jesús y los inicios del humanismo moderno, en M. ${ }^{a}$ L. Amigo Fernández de Arroyabe (ed.), Humanismo para el siglo XXI: Propuestas para el Congreso Internacional. Bilbao: Universidad de Deusto.

Kolvenbach, P.-H. (2000). El servicio de la fe y la promoción de la justicia en la educación universitaria de la Compañía de Jesús de Estados Unidos. Recuperado de: http://www.cerpe.org.ve/tl_files/Cerpe/contenido/documentos/Claves\%20Universidad\%20Ignaciana/Kolvenbach,\%20P.H.\%202000\%20-\%20Servicio\%20Fe\%20 y\%20Promocion\%20Justicia\%20Ed\%20Sup $\% 20$-Santa\%20Clara.pdf 
La Bella, G. (2019). Los jesuitas. Del Vaticano II al Papa Francisco. Bilbao: Mensajero. Llorca, B. et al. (1999). Historia de la Iglesia Católica, V. Edad Contemporánea. Madrid: BAC, 328-331.

López Pego, C. (1994). Historia del Colegio de Villafranca de los Barros. Villafranca de los Barros: Colegio San José, 106-124.

López Pego, C. (2003). Los Jesuitas en Ciudad Real 1903-1986. Ciudad Real: Diputación Provincial.

López Pérez, L. (Compilador) (2005). Radio ECCA, cuarenta años de Historias. Las Palmas: ECCA.

Loyola, S. I. de (2013). Obras. Madrid: BAC. 2013, 390.

Lozano Navarro, J. J. (2005). La Compañía de Jesús y el poder en la España de los Austrias. Madrid: Cátedra.

Lull Martí, E. (1997). Jesuitas y pedagogía. El Colegio San José en la Valencia de los años veinte. Madrid: Universidad Pontificia Comillas.

Mañas, F. J. (2009). La Compañía de Jesús en Almería (1910-2010). El Preconcilio: los PP. Martínez y Rodríguez, 'P. Carbonilla'. Anuario de Historia de la Iglesia andaluza, 2, 305-350.

Marín Cara, A. (2010). La comunidad de jesuitas de Almería en la etapa 1929-1939. Almería: Universidad.

Martínez, A. J. (2006). La Huelva del Padre Laraña. Huelva.

Mier-Terán, C. (2004). José M. ${ }^{a}$ Mier-Terán, S.J., un jerezano para recordar. Madrid: Gráficas Cofás.

Osuna, J. (1998). Amigos en el Señor unidos para la dispersión. Génesis de la comunidad de la Compañía de Jesús y su expresión en las Constituciones, desde la conversión de san Ignacio (1521) hasta su muerte (1556). Bilbao / Santander: Mensajero / Sal Terrae.

Pavone, S. (2005). The Wily Jesuits and the Monita Secreta: The Forged Secret Instructions of the Jesuits: Myth and Reality. Saint Louis, MO: Institute of Jesuit Sources.

Pavone, S. (2006). Between History and Myth: The Monita Secreta. En John W. O’Malley, S.J., Gauvin Alexander Bailey, Steven J. Harris, y T. Frank Kennedy, S.J., The Jesuits II: Cultures, sciences, and the Arts, 1540-1773. Toronto: Ed. University of Toronto Press, 50-65.

Pego Puigbó, A. (2007). Pedro Poveda en clave historiográfica: un debate cultural y pedagógico del siglo XX. Hispania Sacra, LIX, 120, julio-diciembre, 707-740.

Provincia de Andalucía, 50 años: 1924-1974, Granada 1974.

Renau Manén, J. (2003). Pedro Closa. Jesuita y Gitano. Barcelona: Cristianisme i Justícia.

Revuelta González, M. (1991). La Compañía de Jesús en la España Contemporánea. Tomo II: Expansión en tiempos recios (1884-1906). Madrid: Sal Terrae / Mensajero / Universidad Pontificia de Comillas.

Revuelta González, M. (2006). Atención a los marginados en los colegios de jesuitas. Razón y Fe, 1297, 213-229.

Revuelta González, M. (2008). La Compañía de Jesús en la España Contemporánea. Tomo III: Palabras y Fermentos (1868-1912). Madrid: Universidad Pontificia Comillas, Sal Terrae, Mensajero. 
Reyes, M. de los (2013). La casa social católica de Valladolid (1881-1946). Renovación social y presencia cristiana. Madrid: Ediciones Encuentro.

Reyes, M. de los (2020). Una luz encendida en la ciudad. Marcelino de la Paz, S.J. (1842-1932). Madrid: Encuentro.

Roda, L. (2000). Gijón, las luces de la ciudad: biografías gijonesas. Gijón: Gran Enciclopedia Asturiana.

Rodríguez Molina, J. (Ed.) (2009). Curas obreros: la cruz del martillo. Alcalá la Real: Zumaque.

Royo Sánchez, J. (1996). Historia de Nazaret. 40 años de Historia en Alicante. Parte I: 1957-1977. Alicante: Ayuntamiento.

Ruiz Rodrigo, C. y Palacio Lis, I. (1986). Las semanas sociales: una respuesta a la educación del obrero católico. En Varios, Iglesia y educación en España. Perspectivas históricas. IV coloquio de Historia de la Educación, Palma septiembre 1986, Departamento de Pedagogía, I.C.E. de la Universidad de Les Illes Balears, Tomo I, pp. 285-286.

Sancho de Claver, C. M. (2014). La Compañía de Jesús en Fontilles (1909-2014). Bilbao: Mensajero.

Sanz de Diego, R. M. ${ }^{a}$ (1979). La iglesia española ante el reto de la industrialización. En R. García Villoslada (dir), Historia de la Iglesia en España, Vol. 5 (La Iglesia en la España Contemporánea. 1979), dirigido por V. Cárcel Ortí. Madrid: BAC, 577-664.

Sanz de Diego, R. M. ${ }^{a}$ (1993). ICAI-ICADE. Un centro educativo complejo y plural. en Eusebio GIL, La Universidad Pontificia de Comillas, Madrid: Universidad Comillas.

Soto Artuñedo, W. (2004). La actividad de los jesuitas en la Málaga Moderna (15721767). Córdoba: CajaSur.

Soto Artuñedo, W. (2006). P. Jorge Lamothe López-Arroyabe S. I. (Málaga, 20 de mayo de 1927 - Granada, 6 de agosto de 2000). In memoriam, Isla de Arriarán: revista cultural y científica, 27, 9-24.

Soto Artuñedo, W. (2007). El colegio jesuita de San Estanislao en Málaga (1882-2007). Málaga: Colegio San Estanislao, 313-338.

Soto Artuñedo, W. (2008). El Patronato San José para obreros católicos. Jábega 96, 23-35.

Soto Artuñedo, W. (2008). Leyenda negra de los jesuitas. Proyección. Teología y mundo actual, $L V, 373-396$.

Soto Artuñedo, W. (2009). La promoción cultural de los trabajadores. Andalucía en la Historia, VII/4, 32-35.

Soto Artuñedo, W. (2009). Educación popular en Málaga El Patronato y Escuela San José (1906-2006). Málaga: Diputación.

Soto Artuñedo, W. (2017). El apostolado ignaciano de la educación: Institutio puerorum para la reformatio mundo. Manresa 89, 317-328.

Valencia Moreno, G. (2004). Los Javieres de Sevilla, 50 años de Historia. Sevilla: Artes Gráficas Gandolfo.

Valencia Moreno, G. (2006). La gratitud por bandera. Memorias de un hombre con suerte. Málaga: Nuevo Sol de Marbella.

Valencia Moreno, G. (2012). Puentes de Amor en Sevilla. Madrid: Cultiva Libros S.L. 
Valero Agúndez, U. (2012). El proyecto de renovación de la Compañía de Jesús (19652007). Santander: Salterrae.

Varios (1976). Radio ECCA. Centro docente. Las Palmas de Gran Canaria: Radio ECCA.

Varios (1983). P. Antonio de Víu, S.J. Su vida y su obra. 1898-1980. Jerez de la Frontera: Hermandad de Amor y Sacrificio.

Varios (2007). Pilarica, un barrio de Valladolid con historia. Valladolid: Asociación de Vecinos Pilarica.

Varios (2008). IBS Padre Rubinos. 90 años de caridad. La Coruña: Obra Social Caixa Galicia.

Varios (2008). La torre de la Universidad Laboral de Gijón (Del n 1 publicado el domingo 31 de enero de $1960 \mathrm{al} \mathrm{n}^{\circ} 76$ publicado el domingo 7 de abril de 1963). Gijón: Asociación de Antiguos Alumnos de la Universidad Laboral de Gijón.

Varios (2009). Círculo Católico de obreros de Burgos 1883-2008 (actos conmemorativos del 125 aniversario). Burgos: Círculo Católico de Obreros.

Varios (2014). ETEA 50 años. 1963-2013. Córdoba: Diario Córdoba / Diputación.

Varios (2015). 50 años caminando juntos ;Acompáñanos! 1965-2015. Zaragoza: Parroquia Nuestra Señora de Belén.

Varios (2015), En Compañía. Jesuitas - SAFA-Úbeda. Úbeda: DidaCBook.

Verdoy, A. (2005). 50 años de presencia de la Compañía de Jesús en El Pozo del Tío Raimundo. Madrid: Provincia de Castilla. Compañía de Jesús.

Vila, I. (1995). Sant Ignasi (Sarriá). Història d'un col.legi centenari. Barcelona: Novoprint, 160-162.

Viña Herbón, L. (2000). El Natahoyo en el 2000. Gijón: Grupo Foto-Cine «Villa de Gijón». 